\title{
Che Guevara e sua Contribuição ao Desenvolvimento Científico e Tecnológico em Cuba
}

Tirso W. Sáenz ${ }^{1}$

\section{Antecedentes}

Em 1959, a indústria cubana apresentava uma situação de dualismo tecnológico: a produção artesanal coexistia com a produção mecanizada - obsoleta em muitos casos - e com a tecnologia moderna. Isso resultava do modo de produção, das relações de produção e da dependência com relação aos Estados Unidos por parte da economia e da sociedade cubana. O traço mais característico dessa situação era uma acentuada dependência tecnológica, na qual, face à ausência de uma infraestrutura para atividades de $\mathrm{P} \& \mathrm{D}$, impedia uma assimilação ativa da tecnologia que se transferia. A escassa pesquisa que se realizava nas universidades cubanas era produto do esforço pessoal de determinados professores e não se vinculava, em geral, aos temas necessários para a economia do país, mas sim com os interesses acadêmicos dos pesquisadores (Sáenz \& García Capote 1989 pp. 47-48).

\section{As Concepções e as Ações do Che na Esfera Científica e Tecnológica}

A necessidade de desenvolver e impulsionar a economia cubana impôs ao governo Revolucionário a recuperação de estabelecimentos industriais cujos proprietários abandonaram o país nos primeiros meses posteriores ao triunfo da Revolução. Esse fato, junto com as posteriores nacionalizações, em 13 de outubro de 1960, levou à criação do Ministério

\footnotetext{
${ }^{1}$ Cubano, Graduado em Engenharia Química- Rensselaer Polytechnic Institute (1954) e Doutor em Ciências pelo Ministério de Educação Superior (1981). Vice-ministro do Ministério de Indústrias (1962-1965), Vicepresidente da Academia de Ciências de Cuba (1962-1985) Professor Visitante do Instituto Superior de Ciências e Tecnologias Nucleares de Havana, Professor do Instituto Superior Tecnológico de Havana, Professor Visitante da UNICAMP (1996) e Colaborador externo do Centro de Sustentável da UnB. E-mail para contato: tirsowsaenz@gmail.com.
} 
de Indústrias, em janeiro de 1961, no qual se concentrou a quase totalidade da produção industrial existente em Cuba naquele momento. Para dirigi-lo, foi designado Ministro o Comandante Ernesto Che Guevara.

$\mathrm{Na}$ vida e obra do Che há aspectos menos conhecidos que podem contribuir para a compreensão de sua multifacetada personalidade. Um desses aspectos é, precisamente, sua participação direta na construção da base técnico-material do socialismo em Cuba e, em particular, sua gestão como Ministro de Indústrias. Nesta função, ele desempenhou um importante papel no processo de industrialização cubano e, vinculado ao mesmo, na promoção e organização do processo científico e tecnológico no país. Tudo isso, de acordo com as concepções do Che, deveria se basear em um profundo desenvolvimento da consciência dos cidadãos e no papel destes como atores centrais e objetivo principal na construção da nova sociedade socialista.

No Encontro de Solidariedade Afro-asiática realizado em Argel, em 1965, Che defendeu com firmeza que:

No aspecto econômico, necessitamos vencer o caminho do desenvolvimento com a técnica mais avançada possível. Não podemos nos propor a seguir a escala ascendente da humanidade desde o feudalismo até a era atômica e automática, porque seria um caminho de grandes sacrifícios e parcialmente inútil. A técnica há que buscá-la onde esteja; há que dar o grande salto técnico para ir diminuindo a diferença que hoje existe entre os países mais desenvolvidos e nós (Guevara, 1966a, pp 145).

Com base nessa ideia estratégica, no final de 1962, Che criou o Vice-ministério para o Desenvolvimento Técnico, no qual se deveriam dar os primeiros passos para solucionar questões de natureza científica e tecnológica associadas à realização das ações estratégicas para o desenvolvimento industrial do país. Era cada vez mais evidente que, para as viabilizar, seria imprescindível criar uma infraestrutura adequada de pesquisa, geração, transferência e assimilação de tecnologias. (ver Sáenz \& García Capote, 1980).

Por outro lado, desde o princípio deste Vice-ministério, Che destacava a vinculação política e ideológica das atividades científico-tecnológicas:

Cada uma das etapas do desenvolvimento da sociedade socialista está baseada em dois aspectos: primeiro, a compreensão cabal do papel do proletariado na construção do socialismo e, segundo, no desenvolvimento acelerado da nova técnica (Guevara 2001, p. 43). 
Nesse sentido, Che assim se expressava:

O desenvolvimento das pesquisas tecnológicas está orientado não apenas para resolver questões imediatas e conhecer melhor os recursos naturais do país, mas para colocar-se em dia com os avanços daquelas disciplinas que à primeira vista oferecem mais perspectivas à indústria e, seguidamente, fazer pesquisas próprias, experimentos. Buscar a variante técnica cubana que se compare favoravelmente às estrangeiras. Em outras palavras, criar as bases para o desenvolvimento de uma tecnologia própria, de acordo com os recursos, imaginação e capacidade criadora (Guevara 1966b, pp. 673-674).

O Vice-ministério de Construção Industrial, existente desde o início do Ministério de Indústrias, cumpria parte dessas atividades, especialmente no que se relacionava com os processos de transferência de tecnologia.

Ao Vice-ministro para o Desenvolvimento Técnico foi atribuída a tarefa de criar e desenvolver os institutos de pesquisa e outras unidades afins que deviam prover, em suas distintas áreas de atuação, a base adequada para abordar as linhas mestras de desenvolvimento científico e tecnológico que se colocavam e iam sendo definidas de acordo com as necessidades e orientações políticas da revolução.

\section{A Organização do Vice Ministério para o Desenvolvimento Técnico}

Entre as orientações do Che que ainda podemos considerar válidas - relacionadas com as atividades fundamentais que este Vice Ministério deveria realizar, estavam:

- Impulsionar o desenvolvimento técnico do país e a conexão das distintas áreas de ciência e tecnologia com os setores produtivos;

- Manter uma estreita coordenação entre pesquisa e produção;

- Assentar as bases organizativas para que os centros de produção de P\&D do ministério pudessem alcançar maior nível de profundidade e de diversificação em seus estudos;

- Dirigir e executar os panos de capacitação de todo o ministério; e,

- Desenvolver as atividades de normatização. (Guevara 1966b, p 589-590)

Para cumprir estas funções, o Vice-ministério era composto por Institutos de Pesquisa e Direções com perfil normativo e metodológico, além das funções executivas. Um Conselho de Direção, com participação de todos os diretores das unidades vinculadas, dava um caráter participativo às decisões mais importantes. 
Os Institutos e Direções que foram criados são os seguintes:

- Instituto Cubano de Recursos Minerais (ICRM);

- Instituto Cubano de Pesquisas Minero-Metalúrgicas (ICIMM);

- Direção de Automatização Eletrônica (DAE);

- Instituto Cubano de Desenvolvimento de Maquinarias (ICDM);

- Instituto Cubano dos Derivados da cana-de-açúcar (ICIDCA);

- Instituto Cubano de Desenvolvimento da Indústria Química (ICDIQ);

- Instituto Cubano de Pesquisas Tecnológicas (ICIT);

- Direção de Normas e Metrologia;

- Direção de Capacitação;

- Direção de Colaboração Técnico-Científica;

- Direção do Plano para o Desenvolvimento Técnico.

\section{O Instituto Cubano de Recursos Minerais (ICRM)}

Em 1961 foi criado o primeiro centro de pesquisas do Ministério de Indústrias, o Instituto Cubano de Recursos Minerais (ICRM), o que mostra a importância estratégica desta área. Tinha como objetivo acometer, com critérios científicos e práticos, a investigação, prospecção e busca de minerais. Antes da Revolução essas atividades estiveram, fundamentalmente, em mãos de empresas estrangeiras. Durante um tempo, até a criação do Instituto Cubano do Petróleo-ICP, a prospecção e busca de petróleo esteve sob a responsabilidade do ICRM.

Durante seus dois primeiros anos de trabalho, o ICRM, teve um pobre desempenho e não se observou progresso sensível em suas funções. No entanto, era necessário levar em conta que suas atividades eram muito variadas, distribuídas por todo o país em dezenas de unidades de prospecção e busca de minerais sólidos, de perfuração e extração de petróleo, de brigadas de geofísica de diferentes tipos, incluindo a sísmica no mar. Por sua própria natureza, são atividades que se desenvolvem inevitavelmente em lugares intrincados, longe de centros populacionais. Quase sempre, havia que abrir caminhos para transportar os equipamentos, construir facilidades temporais com condições mínimas de moradia, garantir a logística para o fornecimento de alimentos, combustíveis, materiais de trabalho, peças de reposição, entre 
outros desafios. Essas tarefas múltiplas se acometiam sem experiência prática alguma. As atividades do ICRM surgiram como uma explosão gigantesca.

A carência de mão de obra técnica qualificada era enorme no setor de mineração. No Ministério havia apenas dois geólogos cubanos, os quais, até esse momento, estavam ocupados nas atividades produtivas da Empresa de Mineração. Evidentemente eram insuficientes frente às tarefas a realizar. Nessas condições, o forte contingente de especialistas soviéticos e checoslovacos teve um papel relevante no desenvolvimento do setor em Cuba.

As atividades de prospecção e extração de petróleo no Instituto Cubano do Petróleo (ICP) eram dirigidas por especialistas latino-americanos, principalmente argentinos. Inclusive o Subdiretor para esta atividade era um geólogo argentino. Ao passar esta atividade para o ICRM, produziu-se um choque violento, uma guerra declarada, às vezes muda, sobre critérios técnicos - com muito fundo ideológico - entre os especialistas do ICP e os do campo socialista. Havia diferenças que pareciam insolúveis. Essas desavenças também contribuíram para dificultar o avanço dos trabalhos do ICRM em seus primeiros tempos.

Nessa nova fase do ICRM, em 1963, o Che colocou a busca de petróleo e a confecção do Mapa Geológico de Cuba como prioridades para o Instituto, considerando aspectos práticos de nossa economia, como o incremento de reservas e a prospecção de jazidas cujos minerais pudessem substituir importações ou gerar divisas.

Ao apresentar suas orientações para 1964 (Guevara 1966c, p.78), Che voltou a insistir na busca de petróleo e destacou uma atividade vinculada a seu sonho de construir uma planta siderúrgica: criar condições para a busca massiva de minerais ferrosos. Nesse ano, visitei os poços de petróleo de 5 mil metros de profundidade - as maiores profundidades de perfuração até aquele momento - que se realizavam no Cayo Francés. Aí pude comprovar as difíceis condições de trabalho daqueles perfuradores e técnicos.

Para 1965 (Guevara 1966d, p.78) foi dada a este Instituto uma tarefa de maior complexidade e, ainda hoje, de grande relevância: criar as bases organizativas e técnicomateriais para a perfuração no mar, particularmente na zona das pequenas ilhas da costa norte da antiga província de Las Villas. A busca de petróleo foi uma prioridade permanente nas orientações do Che, o qual combinava a busca de resultados imediatos com a visão estratégica.

Nesse ano também foram dadas ao Instituto diretivas concretas para a busca de minerais raros, que seriam importantes como base para o desenvolvimento de uma futura 
indústria eletrônica à qual se atribuía importância particular. Note-se outra vez, como o Che, em suas projeções, vai interconectando as diferentes unidades do Ministério em apoio às ideias estratégicas centrais.

Assim, além de se iniciar um programa sério, com métodos e equipamentos modernos, para a prospecção de petróleo, ampliaram-se os estudos sobre as reservas de níquel, cobre, cromo e minerais não metálicos.

Che apoiou também a organização de exploradores populares, buscando incentivar a incorporação massiva, principalmente de jovens, na busca de minerais, com finalidade educativa e vocacional.

Ao analisar as atividades do ICRM, em novembro de 1963, Che destacou, entre vários aspectos, que se notava um novo espírito no Instituto, reflexo do trabalho de Suárez Gayol, seu diretor - de sua fé e entusiasmo no trabalho, expressão de seu carácter, e de sua impressionante capacidade de comunicação. Este havia logrado unificar os critérios de todos os especialistas e melhorar substancialmente a parte organizativa face aos problemas existentes, além do trabalho científico que fora realizado. Esta avaliação foi reafirmada em análises posteriores feitas pelo Che (Guevara 1966e p.79).

A colaboração soviética no campo geológico foi muito ampla, tanto na transferência de conhecimentos científicos e tecnológicos, como de recursos financeiros e humanos e na formação de especialistas. Em 1965, fui encarregado de viajar à URSS para negociar, em nome do Governo, a obtenção de um crédito de 20 milhões de rublos para a compra de equipamentos de perfuração de petróleo, o qual nos foi concedido.

Um grupo numeroso de especialistas soviéticos foi enviado a Cuba. Eles trabalharam principalmente nas áreas de petróleo e minerais metálicos. Atuaram em todos os níveis - de assessores do Instituto, até à base, nas brigadas de prospecção e perfuração. A colaboração checoslovaca foi também importante, principalmente na área de minerais não metálicos. Em 1964, o ICRM tinha 153 especialistas estrangeiros.

Che contou com a valiosa assessoria de um geólogo checoslovaco, Pedro Kveton, que esteve em Cuba por mais de quatro anos. Ele não se limitava a assessorar ao Che, mas também dava importante ajuda aos demais vice-ministros e diretores de empresas e institutos. Trabalhava intensamente, conhecia Cuba muito bem e, sobretudo, conhecia as características e idiossincrasias do cubano. Por sua recomendação se criou a Comissão Nacional de Reservas Minerais, assim como o Fundo Geológico, os quais inicialmente eu presidi. 
O Ministro de Geologia da antiga Checoslováquia, Josef Pravda, muito contribuiu para materializar uma efetiva colaboração, tanto com o ICRM como com a Empresa de Mineração.

Resultaria muito extenso descrever todas as atividades desenvolvidas pelo ICRM, muitas delas pioneiras em Cuba. Pode-se dizer que esses esforços iniciais foram a base para o crescimento da produção petroleira - de umas poucas dezenas de milhares de toneladas durante os anos 60s, Cuba chegou, no ano 2003, a quatro milhões de toneladas ${ }^{2}$ - além de assegurar muitos minerais de importância para a economia, como os lateríticos para a indústria do níquel.

Um dos resultados científicos a destacar no ICRM foi a obra La Geologia de Cuba, publicada em 1964, impulsionada pelo Che desde a criação do instituto, por sua compreensão da necessidade de um embasamento científico para as tarefas de prospecção de minerais. No prólogo desse livro, ele ressaltou a importância da colaboração com os países socialistas nessa área. Por seu profundo significado e projeção latino-americana, incluindo sua própria decisão de participar diretamente dos movimentos de liberação nacional, transcrevemos in extenso suas palavras:

\begin{abstract}
A importância deste livro é, precisamente, a demonstração da magnitude do apoio que podem prestar entre si os países do campo socialista; em que Cuba, país interessado e sem nenhum desenvolvimento nestas técnicas, possa, aos cinco anos da revolução, apresentar uma geologia de alto nível científico para uso de todos seus futuros profissionais. É o verdadeiro milagre da época que vivemos; o milagre que realiza o homem; o da sua solidariedade; a expressão da potência de sua força conjunta; de sua capacidade de eliminar as barreiras geográficas e transferir a ciência de um país a outro, sem condições, sem outro fim que a ajuda fraterna a outros povos do mundo.

Para nós, os cubanos, a ajuda prestada pelos cientistas de todos os países irmãos tem sido fundamental e tem deixado dois ensinamentos preciosos: o da técnica que possuem e o da solidariedade que implica. nossa jovem revolução, como uma esponja, ávida de todos os conhecimentos de todas as partes do mundo, se impregnará nos largos canais da ciência socialista e da solidariedade socialista para a repartir, no momento oportuno, por parte do continente americano que ainda espera por sua liberação (Guevara, 1966f, pp741-743).
\end{abstract}

\title{
O Instituto Cubano de Investigações em Mineração e Metalurgia (ICIMM)
}

O Instituto Cubano de Investigações em Mineração e Metalurgia (ICIMM) foi criado em 1962 e representava uma complementação fundamental ao trabalho do ICRM. Tinha o objetivo de desenvolver tecnologias adequadas para o processamento de recursos minerais próprios, em particular dos lateríticos, de acordo com as prioridades estabelecidas na linha

\footnotetext{
${ }^{2}$ Cuba produz atualmente $50 \%$ do petróleo que necessita.
} 
estratégica relativa à metalurgia. Pensava-se, dessa forma, no tratamento integral desses minerais. Ou seja, além da prospecção e busca, era também importante viabilizar tecnologicamente a utilização dos minerais em função do desenvolvimento do país.

Consequentemente, as tarefas fundamentais estabelecidas para este instituto em seus primeiros anos foram:

- Trabalhar na metalurgia total das lateritas com vista a seu aproveitamento integral.

- Buscar técnicas não convencionais de redução, como o ferro-esponja, ante a evidente falta de carvão coque que pudesse servir de matéria-prima para a indústria siderúrgica. Che considerou que isso poderia ser um passo importante nessa área desenvolver novas tecnologias de beneficiamento para os minerais de cobre, manganês e minerais não metálicos.

- Desenvolver uma tecnologia e um projeto de inversões que permitisse assegurar o abastecimento na ampliação da empresa "Antillana de Acero".

- Estudar as modificações necessárias na planta de "Sulfometales", para incrementar a recuperação e produção de cobre e outros metais (Guevara 1966g, p. 641).

As duas primeiras atividades representavam as tarefas sobre as quais se deveria atuar com maior intensidade.

Para o Che, encontrar materiais substitutos no campo da siderurgia poderia ser um passo muito grande em nosso desenvolvimento. A ideia era produzir o chamado "ferro esponja", ou seja, um ferro com as características do ferro-gusa utilizando agentes redutores diferentes do coque: antracite, carvão vegetal - até o bagaço da cana chegou a ser considerado -, e processado em fornos rotatórios em vez de altos fornos. Buscava-se desenvolver um processo similar ao que se utilizava no México. Na sede do ICIMM, na cidade de Havana, foi instalado um forno piloto rotatório com esse objetivo.

Ao apresentar suas Orientações para 1964, Che voltou a insistir no desenvolvimento dos trabalhos sobre ferro-esponja e nos estudos sobre a redução direta do mineral de ferro, além de outros aspectos tecnológicos que pudessem viabilizar uma indústria siderúrgica em Cuba. Também orientou que se fortalecessem os trabalhos de pesquisa sobre os processos tecnológicos do níquel, assim como os das lateritas em geral, indicando que esses trabalhos, até então realizados pela Empresa Consolidada do Níquel, passassem à responsabilidade do ICIMM (Guevara 1966e, pp. 612). 
Para dirigir o ICIMM, foi nomeado Faustino Prado, um engenheiro metalúrgico de altos conhecimentos técnicos. Ele havia conversado extensamente com o Che sobre o que se poderia alcançar na produção de ferro-esponja. Durante cerca de dois anos, trabalhou-se neste processo, ainda que de forma pouco sistemática, sem resultados promissores.

Nesse período, tampouco houve resultados de importância nos outros objetivos do ICIMM. Nada se fez, concretamente, para desenvolver os trabalhos sobre o processamento de níquel, uma das prioridades do Ministério. Em algumas plantas piloto da Empresa de Mineração se alcançaram resultados mais significativos, sem que em neles o ICMM tivesse participação alguma.

O ICIMM não estava devidamente estruturado, e tinha um baixo potencial de recursos humanos para empreender tantas tarefas prioritárias. Administrativamente, o Instituto funcionava mal e o diretor não conseguia coordenar o muito escasso pessoal técnico para colaborar na execução dos trabalhos de desenvolvimento tecnológico. Ele foi um dos especialistas que se haviam incorporado às tarefas do Ministério sem possuir vínculos ideológicos com a Revolução, mas o Che lhe ofereceu todo apoio sem exigência de condições políticas.

Deve-se ressaltar que a inexperiência em lidar com atividades de desenvolvimento tecnológico teve uma grande influência no que ocorreu no ICIMM. Independentemente das deficiências administrativas, era impossível esperar resultados tecnológicos daquela magnitude com apenas dois ou três anos de trabalho.

Uma boa parte das tarefas do ICIMM teve continuidade no atual Centro de Pesquisas para a Indústria Minero-Metalúrgica (CIPIMM). A fábrica de Nicaro foi desativada como processadora de minerais lateríticos, ainda que suas importantes oficinas mecânicas tenham sido mantidas.

Penso que a ideia do Che de produzir, com recursos minerais próprios, matéria-prima para a indústria siderúrgica, pode ser ainda atual. Valeria a pena, agora que se dispõe de pesquisadores experientes, dedicar alguns esforços para retomar essa ideia e desenvolver tecnologias que nos permitissem reduzir grandes importações de ferro-gusa, criar fundos exportáveis e contribuir ao desenvolvimento da indústria sideromecânica. 


\section{A Direção de Automatização e Eletrônica (DAE)}

Em 1962 criou-se a Direção de Automatização e Eletrônica (DAE). Essa Direção, além de suas funções metodológicas e de realização de estudos prospectivos, tinha objetivos e exercia atividades próprias de um instituto, com orientação setorial. Posteriormente, transformou-se no Centro de Automatização Industrial (CAI) - outra das linhas estratégicas promovidas pelo Che -, e desempenhou um papel pioneiro neste campo, de modo particular, ao contribuir para a formação, na Escola de Automatização, dos primeiros técnicos de nível médio e superior especializados em controle automático em nosso país.

Em 1963, foram atribuídas a essa Direção tarefas que lhe permitiram fortalecer seu potencial humano e material e, ao mesmo tempo, fazer contribuições práticas à Indústria. Por indicação do Che, iniciaram-se atividades de estudos, reparação e manutenção de todos os meios de controle industriais que existiam no país. Também atuou na preparação de pessoal técnico que formaria a base para iniciar estudos concretos de automatização em distintos setores industriais. Também se iniciaram os estudos sobre a possível instalação, no curto prazo, de fábricas de componentes eletrônicos (Guevara 1966b, p.589).

Nesse mesmo ano, a Empresa Consolidada de Equipamentos Elétricos foi orientada a desenvolver produtos eletrônicos, contando com a perspectiva de uma rápida instalação de indústrias desse tipo em Cuba.

Em 1964 e 1965, as atividades da DAE foram mais precisas e de maior alcance, entre elas (Guevara 1966e, p. 610 e Guevara 1966e, p. 638):

- Começar estudos concretos sobre a Automatização da indústria açucareira, a partir de esquemas simples e, posteriormente, estabelecer controles pneumáticos e hidráulicos nessa indústria.

- Preparar as condições para o estudo aprofundado do estabelecimento de uma indústria eletrônica desenvolvida.

- Dirigir a Escola de Automatização.

Em suas conclusões sobre o informe do Vice ministério de Desenvolvimento Técnico, Che reforçou as tarefas para a DAE, indicando que esta deveria iniciar um novo rumo no trabalho: o desenvolvimento de computadores e componentes, assim como o desenvolvimento de todo o campo da automatização na esfera econômica e administrativa - uma das ideias 
básicas para eliminar a burocracia -, bem como desenvolver um plano de automatização das indústrias com base em nossas possibilidades.

Observe-se novamente como se busca conjugar as tarefas de solução imediata com os trabalhos e estudos prospectivos. Esta era uma das características básicas das orientações colocadas pelo Che às unidades encarregadas do desenvolvimento científico e técnico, e era a tônica geral que se imprimia às distintas atividades a serem realizadas pelo Ministério de Indústrias. Por outra parte, uma vez mais, fica evidente a ansiedade do Che por "queimar etapas", querendo avançar muito mais do que parecia possível.

O diretor selecionado inicialmente para esta Direção tinha um mestrado em Engenharia Elétrica numa importante universidade norte americana. Ele foi também um dos quadros técnico que ficaram em Cuba, sem formação política, mas disposto a colaborar com a Revolução. Eu reconhecia que ele tinha conhecimentos técnicos suficientes para enfrentar as tarefas que lhe foram assignadas, mas tanto suas concepções de trabalho, assim como a conjugação das tarefas imediatas e perspectivas, careciam de objetividade e solidez; ademais, faltava-lhe capacidade gerencial. Seu trabalho como dirigente era débil, ainda que alguns trabalhos importantes tenham sido realizados, principalmente devido à abordagem e ao esforço de um especialista checoslovaco que realizou alguns estudos prospectivos muito interessantes e úteis.

O Che estava muito insatisfeito com o trabalho desenvolvido pela DAE. Em sua opinião, a Direção não havia realizado nada novo e não era capaz de organizar o que já existia. Desenvolver o campo de Automatização era outro dos sonhos dourados do Che que não mostrava resultados tangíveis.

Devido a estas circunstâncias, o diretor substituído, ficando como especialista na própria DAE. Seu substituto havia realizado um bom trabalho dentro da Direção de Capacitação. Ele havia iniciado os estudos de Medicina, que abandonou para incorporar-se às lutas revolucionárias. Tinha um bom sentido de organização e de gerenciamento, o que mais se necessitava naqueles momentos. Imediatamente, as lutas internas foram superadas e trabalhos da Direção se desenvolveram de forma adequada.

\section{O Instituto Cubano de Desenvolvimento de Maquinaria (ICDM)}


O ICDM foi criado em 1963 com o objetivo de apoiar o desenvolvimento da indústria mecânica, fortalecendo as atividades para a criação da base industrial do país. Entre as orientações para esse ano (Guevara 1966b, p.589), Che destacou o desenvolvimento de um projeto de fabricação de peças de reposição elaborado por um grupo de assessores soviéticos, alem das atividades de controle para o melhor aproveitamento das máquinas-ferramenta do organismo. Estas tarefas estavam vinculadas diretamente à atividade produtiva, foco de atenção, manifestada em forma diversa em todos os centros de investigação do Ministério. Aproveitava, também, o forte grupo de 22 especialistas soviéticos nas questões de fabricação de peças de reposição e sua planificação.

Pode chamar a atenção, no contexto atual, o fato de essas tarefas serem tratadas de forma centralizada. Deve-se levar em conta que, ainda que se criavam novas capacidades em oficinas mecânicas e cursos de capacitação nas diferentes áreas, a experiência das empresas quanto aos tipos de peças necessárias, como e onde produzi-las, era muito escassa. Por isso, tratava-se de elaborar um plano geral de produção de peças de reposição, considerando as prioridades e possibilidades oferecidas pela experiência da assistência técnica disponível, ao mesmo tempo em que se desenvolviam tecnologias para fabricá-las. Essa era uma tarefa complexa para um instituto que apenas iniciava suas atividades, mas era um desafio que permitia ao ICDM ganhar experiência para projetos ulteriores.

Para 1964 (GUEVARA 1966e, p. 612), Che confirmou os propósitos relacionados às peças de reposição e também atribuiu ao ICDM a responsabilidade de articular-se com o Instituto Nacional de Reforma Agrária (INRA) para o desenvolvimento de maquinaria agrícola. As responsabilidades do Instituto aumentavam. Para 1965, destacaram-se, entre outras prioridades, o fortalecimento das atividades relativas às peças de reposição, a continuidade dos trabalhos relacionados à maquinaria agrícola para a cana e o kenaf, assim como a colaboração em um estudo sobre o desenvolvimento perspectivo do Setor Mecânico.

O ICDM marcou uma etapa importante no desenvolvimento da construção de maquinaria em Cuba. Apesar das limitações de todo tipo, foi possível avançar técnica e organizativamente. O Plano de peças de reposição, ainda que elaborado e executado no quadro de uma grande inexperiência, contribuiu para a solução gradual de problemas no setor. Iniciou-se o desenvolvimento de protótipos de cortadoras de cana mais avançadas e foram 
instalados os primeiros centros de colheita e armazenamento ${ }^{3}$ de cana-de-açúcar, que contribuíram posteriormente para aumentar a qualidade da cana recolhida e para a eficiência da produção. Estas não foram as máquinas definitivas, porém abriram caminhos promissores. Esse esforço permitiu, sobretudo, formar pessoal e ganhar uma experiência de grande valor para o avanço da indústria mecânica.

Che, analisando o trabalho do Instituto, ressaltou que se notava um avanço sustentável, o que permitia desenvolver atividades de maior envergadura. Nesse sentido, orientou que se trabalhasse também em processos vinculados à indústria química. (Vice ministério para o Desenvolvimento Técnico 1964, p. 142 e Guevara 1966h, p. 96).

Para dirigir o ICDM foi designado um jovem especialista uruguaio, que era assessor do Vice-ministro para a Indústria Básica no que se referia à indústria mecânica. Seu trabalho foi sério e constante, e seus resultados se mostravam no avanço do ICDM.

Mais tarde as funções e tarefas do ICDM se incorporaram a distintas entidades do Ministério da indústria Sideromecánica, criado no final da década de 1970.

\section{O Instituto Cubano de Pesquisas dos Derivados da Cana-de-Açúcar (ICIDCA)}

O Instituto Cubano de Pesquisas dos Derivados da cana-de-açúcar (ICIDCA) foi outro instituto criado em 1963, em correspondência com as linhas estratégicas do Ministério. Che afirmava que o futuro da indústria açucareira dependia de que os derivados da cana-de-açúcar se convertessem em seu produto principal, ficando o açúcar como um subproduto.

O ICIDCA ocupou as instalações do anterior Instituto Cubano de Pesquisas Tecnológicas, uma instituição criada antes da Revolução, sob auspícios norte-americanos, para apoiar - deliberadamente - um débil desenvolvimento da indústria nacional-, cujas possibilidades de obter resultados eram muito escassas ${ }^{4}$.

Seu primeiro Diretor foi um valiosíssimo engenheiro químico, de elevados conhecimentos científicos e técnicos, ainda que sem vocação administrativa. A tarefa inicial foi muito complexa, modificar as linhas de trabalho do antigo ICIT, que, em muitos casos não

\footnotetext{
${ }^{3}$ Centros de limpeza em seco da cana de açúcar, onde, com ventiladores de grande porte se logra separar cerca de $70 \%$ das folhas, buscando menor volume de matérias estranhas na fábrica e maior rendimento industrial. Atualmente Cuba conta com 680 unidades, em todas as empresas açucareiras do país (Comunicação verbal do Lic. Tirso Sáenz Coopat, presidente da ATAC, 2002 - 2009).

${ }^{4}$ Para uma análise mais detalhada do antigo ICIT, ver Sáenz e García Capote (1989): op.cit.
} 
correspondiam às prioridades do novo Instituto. Esse diretor compreendeu, depois de poucos meses à frente da instituição, que ele não reunia os requisitos administrativos para ocupar o cargo, preferindo voltar a seu antigo cargo de professor. Depois de sua saída do ICIDCA, foi um brilhante professor e pesquisador no Instituto Superior Politécnico "José Antonio Echeverría"5, na cidade de Havana, onde alcançou altas honras, reconhecimentos e condecorações. Nesse Instituto, a cátedra açucareira leva seu nome.

Foi então designado para dirigir o ICIDCA um jovem engenheiro químico, formado numa importante universidade norte-americana. Ele foi também um dos técnicos que ficaram em Cuba, ainda que em seu caso particular, desde o início, mostrou uma definida posição de apoio à Revolução.

O novo diretor deu um impulso notável ao instituto. Ele e eu, com nossa formação de engenheiros químicos, havíamos discutido muito sobre a necessidade de incorporar os centros de pesquisa tecnológica, áreas de desenvolvimento tecnológico experimental: plantas pilotos e oficinas de protótipos, além de equipamentos de engenharia, que deram uma forma mais acabada, próxima à produção das tecnologias que foram desenvolvidas. Além disso, deveriam iniciar-se os estudos de factibilidade técnico-econômica de novos processos ou produtos, questões que não eram bem compreendidas naquela época.

No ICIDCA ele teve a possibilidade de materializar esta filosofia de trabalho. O desenvolvimento experimental, a engenherização e a avaliação técnico-econômica de projetos foram incorporados. Colocava-se em prática uma novidade para um instituto: uma área de avaliação técnico-econômica e outra de engenharia, as quais trabalhavam com equipes ad hoc para o desenvolvimento final de projetos.

Com o objetivo de estabelecer a necessária base científica e tecnológica, Che insistiu sobre as linhas perspectivas:

...o futuro do ICIDCA está na ênfase cada vez mais crescente dos processos de fermentações que permitam ao instituto ter uma tecnologia avançada neste aspecto. (...) temos que concentrar os esforços para capacitar quadros neste aspecto. (Guevara, 1966i, p. 101).

As primeiras orientações dadas pelo Che ao ICIDCA para 1963 foram: organizar-se perfeitamente; estudar os problemas relacionados aos derivados da cana; articular com os distintos organismos relacionados com esta gramínea e prestar particular atenção ao estudo de

\footnotetext{
${ }^{5}$ Actualmente denominada Universidad Tecnológica de La Habana
} 
novas técnicas de fermentação. Apesar da importância que concedia a essa linha de desenvolvimento, Che colocou que as tarefas deveriam ser realizadas com calma.

Com base em tais indicações, para 1964 (GUEVARA 1966e. p. 612) foram hierarquizadas as seguintes linhas de trabalho: alfa-celulose, matéria-prima que se importava para a produção de rayon ${ }^{6}$; dextrana, para uso clínico e industrial; refinação de cera de cachaça para substituir importações e transformar-se em um possível produto de exportação; fermento torula para a alimentação do gado e carvão ativado para diversos usos industriais.

Quanto ao alfa-celulose a partir do bagaço da cana, trabalhou-se na seleção e adaptação, em escala de micro planta piloto, de uma tecnologia que indicava preliminarmente a possibilidade real de produzi-la em escala industrial.

No caso da dextrana, a planta na Central "España Republicana" fora abandonada sem documentação por uma empresa norte-americana. O ICIDCA a restabeleceu com o apoio de especialistas da RDA, assistência técnica que foi muito bem aproveitada. A planta piloto construída por esse instituto conseguiu produzir, em 1964, 41,1 toneladas, ainda que fosse necessário continuar os trabalhos de desenvolvimento.

Para a refinação da cera de cachaça, com assessoria de um especialista muito qualificado da RDA, foram realizados trabalhos experimentais em pequena escala, os quais deveriam ter continuidade e serem ampliados até alcançar a tecnologia adequada para sua projeção industrial.

No caso do fermento Torula, intensificou-se o trabalho de pesquisa em nível de laboratório e de micro planta. Com base nos resultados iniciais, fez-se um trabalho conjunto com a Empresa Consolidada do açúcar para o projeto e construção de uma planta piloto em uma usina açucareira.

Quanto ao carvão ativado, os trabalhos de pesquisa se concentraram, numa primeira etapa, na possibilidade do uso do pó de bagaço da cana como matéria-prima, prevendo-se a construção de uma planta piloto para continuar as atividades de desenvolvimento.

O avanço do ICIDCA nos primeiros anos foi notável. Che sentiu-se muito satisfeito com os resultados obtidos e avaliou muito positivamente o trabalho realizado. Este instituto ainda se mantém muito ativo no campo da indústria açucareira.

\footnotetext{
${ }^{6} \mathrm{O}$ uso mais importante do rayon naqueles momentos era para a produção de pneumáticos.
} 


\section{O Instituto Cubano para o Desenvolvimento da Indústria Química (ICDIQ)}

Visando o desenvolvimento de tecnologias autóctones, em 1963 foram criados o Instituto Cubano de Desenvolvimento da Indústria Química (ICDIQ) e o Instituto Cubano de Pesquisas Tecnológicas (ICIT). Esses institutos foram dotados de uma base própria de construção de protótipos, plantas piloto e equipamentos tecnológicos, mostrando uma visão adiantada para Cuba - como foi indicado no ICIDCA - sobre a importância do escalonamento nos processos de pesquisa e desenvolvimento tecnológico.

O ICDIQ tinha, entre suas atividades fundamentais, trabalhar em um esquema de desenvolvimento futuro da indústria química; gerar tecnologias próprias, e assegurar a projeção, execução e utilização das plantas derivadas dessas tecnologias, incluindo a fabricação de parte do seu equipamento (GUEVARA 1966b, p. 612).

Este instituto foi concebido com uma estrutura que incluía os laboratórios de pesquisa, as plantas piloto; as oficinas de protótipos e de construção de equipamentos e maquinaria; as áreas de Engenharia de projetos e uma equipe de construção e montagem para as fábricas decorrentes das tecnologias desenvolvidas. Fez-se uma inversão considerável para a época.

Para o Che, a química e a eletrônica eram elementos vitais para o desenvolvimento industrial e econômico de um país. Em 1964, ele colocava que:

(...) não podemos esquecer que somos um país atrasado que tem de desenvolver a química, que é uma mais dentro das coisas que estão atrasadas. Que o ICDIQ se criou para desenvolver a indústria química... Que no momento este instituto no deve ser nada mais que o criador de tecnologias e construtor das fábricas de acordo com sua tecnologia, isto é, desenvolvendo os aparatos e equipamentos necessários. E há de ser também o organismo investidor, quanto a novas plantas (GUEVARA, 1966j, p.98).

Estas palavras do Che refletiam a importância estratégica que ele atribuía ao desenvolvimento da indústria química e a intenção de que este se realizasse de forma relativamente independente dos processos de construção de outras indústrias.

Eu estava de pleno acordo com o Che quanto à concepção organizativa do ICDIQ e aos dois primeiros pontos colocados por ele. No entanto, eu acreditava, assim como muitos companheiros dirigentes do Ministério, que o diretor, mesmo dispondo de indubitáveis conhecimentos técnicos, atuava frequentemente com uma ousadia irresponsável, desenvolvendo "no cheiro", sem claros princípios tecnológicos e estabelecendo prazos impossíveis de serem cumpridos tecnologicamente. 
Era possível compreender a posição do Che. Ansioso como estava por impulsionar o desenvolvimento industrial, dava todo o apoio solicitado para tarefas propostas em áreas prioritárias, quando lhe asseguravam que podiam ser realizadas. Assim como estimulava a classe operária a buscar ideias novas e oferecer soluções para os problemas do país, também tratava de estimular o pessoal de alto nível técnico.

No caso do diretor do ICDIQ, esse estímulo se justificava, especialmente considerando a importância dos empreendimentos que ele propunha, dirigidos fundamentalmente à melhoria da saúde em $\mathrm{Cuba}^{7}$. Sua obra principal nesta Direção foi o projeto e construção de uma planta de antibióticos de diversos tipos, tomando como base as instalações existentes de uma planta de fermento para a fabricação de pães. Projetar e construir uma planta de antibióticos com tecnologia própria, a poucos anos do triunfo da Revolução, em um país que impulsionava prioritariamente a saúde pública, despertava sem dúvidas, um grande interesse. Daí todo o apoio obtido, recebendo todos os recursos que solicitou.

A planta resultou num verdadeiro fiasco. Não se produziu nem uma grama de antibióticos. Depois de muitos esforços inúteis, voltou a ser o que era anteriormente: uma planta produtora de fermento para pães.

Apesar dos péssimos resultados obtidos pelo ICDIQ, é importante recordar que a ideia de estruturar integralmente todos os elementos essenciais dos processos de inovação laboratórios, oficinas de protótipos, plantas pilotos, a construção montagem - era válida. Essa concepção voltaria a predominar, anos depois, com sucesso, no processo integral de pesquisadesenvolvimento-produção para a indústria de fármacos de origem biotecnológica. (SÁENZ, 2005).

\section{O Instituto Cubano de Pesquisas Tecnológicas (ICIT)}

Ainda que com o mesmo nome, este instituto não era uma simples continuidade do ICIT da década dos 50s. Agora ele se organizava em bases distintas. Desde o princípio, segundo as orientações do Che, o novo ICIT foi orientado para o desenvolvimento de tecnologias baseadas, fundamentalmente, em matérias primas de origem vegetal e em subprodutos industriais. A ideia central era criar uma vinculação de desenvolvimento mais

\footnotetext{
${ }^{7}$ Como as plantas de antibióticos, soros e esteroides, todas elas colocadas nas tarefas do instituto.
} 
estreita entre a agricultura - considerada naqueles momentos como pilar fundamental da economia - e a indústria.

Por outra parte, e, em sentido adicional ao estrito trabalho de pesquisa agrícolaindustrial, Che havia destacado em diferentes reuniões de trabalho a importância de introduzir gradualmente na prática agrícola de nosso país os métodos de Direção industriais - geralmente mais avançados em relação aos usados na agricultura - mediante uma vinculação mais orgânica de ambos os setores, entre outras vias, antecipando a ideia dos futuros complexos agroindustriais. Já em 1963, ele havia indicado como prioridade as pesquisas sobre diferentes cultivos.

Partindo-se do zero, iniciou-se a construção dos laboratórios, das plantas piloto e das oficinas. A inclusão dos elementos de desenvolvimento experimental, essencial para poder alcançar os objetivos colocados para a instituição, foi feita pelo primeiro diretor, mas os recursos humanos qualificados eram exíguos.

Quando o diretor foi transferido para dirigir o ICIDCA, não havia candidatos de nível técnico disponíveis para dirigir o ICIT. Propus então ao Che o nome de um companheiro, de quem eu tinha uma magnífica opinião desde que trabalhamos juntos no ICP. Como já explicamos, ante à falta de pessoal capacitado, havia que utilizar companheiros sem preparação técnica, mas com capacidade de direção e entusiasmo para dirigir centros de pesquisa. O novo diretor, apesar de estar enfermo, fez um trabalho intenso, prestando grande atenção à Estação Experimental "Ciro Redondo", vinculada ao ICIT. Dela nos ocuparemos mais adiante.

Lembro-me de que, no final de 1963, em uma reunião sobre o trabalho do ICIT, o diretor perguntou ao Che, qual seria, em sua opinião, a visão de futuro deste instituto. Che meditou por um momento e disse: um ponto no horizonte: o comunismo.

Durante algum tempo, pensei que o Che havia respondido jocosamente à pergunta, $o$ que não era habitual nele. Depois compreendi sua profundidade. Ele não podia, logicamente, dar uma orientação científico-técnica além das que havia dado. Nossa responsabilidade era buscar essa estratégia e a propor. Se se encontrava uma solução adequada e se trabalhava de forma consequente sobre ela, o objetivo a largo prazo do ICIT seria contribuir ao desenvolvimento de uma sociedade comunista, na acepção marxista da palavra. Isso era o que ele queria dizer.

\footnotetext{
${ }^{8}$ Localizada no município de Jovellanos, província de Matanzas.
} 


\section{A Estação Experimental “Ciro Redondo” (ver Sáenz 2004)}

Esta estação, vinculada ao ICIT, tinha um carácter especial. Nela se conjugavam as atividades experimentais agropecuárias com as de desenvolvimento dos produtos agrícolas com fins industriais. Realizavam-se ensaios e se aplicavam métodos de organização do trabalho, dos salários e de estimulação, tomando como critérios os resultados do trabalho agrícola de cada trabalhador (produtividade, qualidade) assim como a capacitação individual, combinando formas de estímulo individual e coletivo.

"Ciro Redondo" foi uma das primeiras unidades com objetivo de experimentação criado pelo Che. Em 1961, ele havia dado instruções para que se selecionasse uma chácara para esses fins, que não estivesse em muito boas condições, para que não se diminuíssem as áreas efetivas de cultivo do então Instituto Nacional de Reforma Agrária (INRA). Assim apareceu, em Jovellanos ${ }^{9}$, a chácara chamada "Maria Luisa"

Em janeiro de 1962 foram selecionados os primeiros 165 trabalhadores procedentes da Escola de Superação do Exército Rebelde e da guarda do Ministério de Indústrias. Quase todos haviam pertencido à Coluna do Che durante a guerra; eram de origem camponesa e possuíam um elevado espírito de trabalho e sacrifício, embora, na quase totalidade, tivessem um grau de escolaridade muito baixo.

A tarefa de resgatar aquele pedregal e colocar seus primeiros 200 hectares produzindo, em um ano, com escassos recursos mecânicos, exigiu um grande esforço do grupo inicial de trabalhadores que, depois de intensas jornadas de trabalho deviam dedicar horas adicionais ao estudo.

Dois anos depois, em 1964 (Guevara 1966d, p. 611), ao precisar os objetivos do ICIT e, em particular, desta unidade, Che destacou que a tarefa fundamental era a agricultura como base para o desenvolvimento industrial e a ciência botânica.

A referência do Che à Botânica evidencia o caráter científico que ele queria imprimir nas pesquisas agrícolas. A articulação com os conhecimentos básicos da agricultura se estabeleceu com a então chamada Estação Experimental Agronômica de Santiago de Las Vegas ${ }^{10}$ e, em particular, com os destacados pesquisadores cubanos Juan Tomás Roig e Julián Acuña Galé.

\footnotetext{
${ }^{9}$ Na província de Matanzas.

${ }^{10}$ Hoje sede do Instituto de Pesquisas Fundamentais em Agricultura Tropical "Alejandro de Humboldt" (INIFAT)
} 
As terras cultiváveis da unidade foram dedicadas fundamentalmente às tarefas de experimentação, extensão ou aclimatação de variedades vegetais de interesse industrial, em duas linhas principais: fibras têxteis - entre elas o rami e o kenaf - e oleaginosas, como o amendoim e a gergelim, para a indústria alimentícia; ou de aplicação em perfumaria e outras indústrias; e o tung e o cartamo para a fabricação de tintas.

Isso dá uma ideia de como começam a se estabelecer na prática algumas das concepções do Che. Fomentou-se uma base experimental agropecuária própria, com vistas ao desenvolvimento de tecnologias de cultivos que servissem de matéria-prima para a indústria e, ao mesmo tempo, encaminhou-se para o desenvolvimento de tecnologias de processamento dos mesmos, ou seja, foram buscados verdadeiros pacotes tecnológicos integrais, que poderiam contribuir ao incremento da cooperação e da integração intersetorial, mediante uma maior utilização de nossos recursos naturais.

Foi-se criando um potencial científico-técnico nesta esfera o qual, ainda que pequeno, abria novos caminhos e impulsionava o desenvolvimento ulterior da agroindústria.

Apesar das limitações em termos de recursos, das necessidades urgentes da produção e da falta de experiência de todo o coletivo, foram se perfilando os elos necessários na atividade de pesquisa-desenvolvimento: laboratórios de pesquisa e de serviços, áreas de extensão agrícola e plantas piloto e ações coordenadas com a indústria. Nessas ações observam-se passos iniciais do que hoje chamaríamos de planejamento a ciclo completo dos processos de inovação tecnológica.

Che enfatizou a necessidade de utilizar a experiência internacional em cultivos tropicais e seu aproveitamento no âmbito da Estação Experimental. Para tal, em 1963 e em 1964 foram realizadas missões ao Brasil, lideradas por Guillermo Cid, para visitar centros experimentais, trazer variedades agrícolas de interesse e estabelecer bases para a cooperação. A última missão coincidiu com o golpe militar que destituiu o presidente Goulart, dando início à ditadura militar. Isso frustrou o seguimento dessas relações. Também, durante esses anos, uma missão de especialistas em fibras vegetais da República Popular da China colaborou na "Ciro Redondo".

O experimento social iniciado nessa unidade sobre a organização do trabalho e dos salários foi de particular relevância. A proposta estava inserida entre os aspectos medulares do pensamento político e econômico do Che. Ele encontrou nessa estação a oportunidade de desenvolver pesquisas sobre suas ideias no setor agropecuário. Suas concepções acerca do 
sistema orçamentário de financiamento, dos métodos de Direção, das formas de estimular o trabalhador, e dos fundamentos político-ideológicos dessas questões foram colocadas em prática. Ao mesmo tempo, eram objeto de uma cuidadosa, profunda e sistemática análise no Ministério, para enriquecê-las, fazer os ajustes, correções e aperfeiçoamentos necessários.

Com esses objetivos, juntamente com o Ministério do Trabalho, preparou-se um estudo que continha, em essência, os seguintes elementos:

- Uma escala salarial e um sistema de normas práticas, baseadas nas normas que eram utilizadas no setor agrícola, com determinados ajustes necessários, para as atividades vinculadas à pesquisa e ao desenvolvimento;

- De acordo com o sistema de pagamento baseado nessas normas, se as metas fossem ultrapassadas, o excedente determinava a quantidade das quotas de benefícios as quais tinham a particularidade de acumular-se em um fundo coletivo de prêmios, que era distribuído em função de determinados índices: a elevação da qualificação, o cumprimento das normas no plano de trabalho, a assistência e pontualidade no trabalho, a qualidade e o rendimento nas colheitas;

- O estabelecimento de dois tipos de prêmios associados ao fundo coletivo; entre os do primeiro tipo se encontravam as casas; entre os do segundo tipo, móveis, rádios, cavalos, etc. Os prêmios do primeiro tipo eram distribuídos entre os trabalhadores de elevada pontuação, de acordo com os índices assinalados anteriormente; os prêmios do segundo tipo eram distribuídos para aqueles que alcançavam uma pontuação média; abaixo de um determinado nível de pontuação não se tinha direito a prêmios. Os recursos do fundo podiam também ser usados para financiar obras de beneficio coletivo como cinemas, círculos infantis e outros.

Essa forma de pagamento tinha o objetivo de relacionar o trabalhador com sua produtividade, com seu interesse em elevar a qualificação, assim como a desenvolver seu espírito coletivo. A recompensa individual era dada na medida em que maior fosse sua contribuição e esforço pessoal considerado integralmente, incluindo as atividades de estudo.

Che costumava visitar a granja mensalmente. Eu o acompanhava, junto com o Diretor do ICIT. Em geral, a primeira parte da visita era dedicada a discutir com o Diretor da Unidade e com Cid sobre o desenvolvimento dos projetos; depois visitávamos as construções e recorríamos a cavalo todos os cultivos. Finalmente, nos reuníamos com os trabalhadores. 
Che discutia pessoalmente com todos eles, seus antigos companheiros de luta, sobre este sistema de organização do trabalho e dos salários, destacando-se a necessidade de incrementar a produção e a produtividade por meio da técnica, da superação, do esforço individual e coletivo. Destacava-se, nesse contexto, o papel do desenvolvimento da consciência social e política. Eram explicações detalhadas, expressas de maneira simples, em um ambiente fraternal entre companheiros de combate.

O ser humano e seu desenvolvimento eram parte integrante deste projeto. Desde o primeiro momento havia um professor para atender sistematicamente e com todo rigor a um contingente de trabalhadores, quase todos analfabetos ou semianalfabetos à época do triunfo da Revolução. Periodicamente, uma psicóloga atendia os casos que apresentavam dificuldades de aprendizagem ou de outro tipo. Também eram realizados exames médicos, incluindo o oftalmológico.

Do trabalho criador dos primeiros anos obteve-se a recuperação de dezenas de hectares cultiváveis, a construção de albergues, do refeitório, de armazéns, instalações para as plantas piloto, além da escola e das primeiras 21 casas a serem distribuídas segundo o sistema de prêmios estabelecido.

A superação e a formação integral daquele grupo inicial de trabalhadores, e de outros que posteriormente se incorporaram, permitiram a criação de uma importante reserva de quadros técnicos que vieram a ocupar cargos em outras áreas.

A Estação Experimental "Ciro Redondo" foi transferida, em 1965, para o Centro Nacional de Pesquisas Científicas (CENIC).

\section{A Direção de Normalização, Metrologia e Controle de Qualidade}

Desde 1960, um grupo de trabalho criado na Junta Central de Planificação (JUCEPLAN) começou a dar os primeiros passos na atividade de normalização, tratando de unificar as especificações de matérias-primas para a indústria.

A Direção de Normalização, Metrologia e Controle de Qualidade foi criada no Ministério antes do Vice ministério para o Desenvolvimento Técnico. Suas tarefas eram essenciais para garantir o desenvolvimento de qualidade na produção industrial. Che destacou, ainda em 1962, que a missão principal desta Direção seria a elaboração de um sistema de normas de insumo de materiais e de qualidade por cada unidade de produto, de acordo com as 
condições tecnológicas das fábricas, priorizando os produtos destinados à exportação (Guevara 1966b, p 591).

Esse trabalho era complexo, não apenas pela variedade, mas também pela interconexão que devia estabelecer com as empresas, as quais, à época, não prestavam a devida importância às questões de normalização e qualidade, dadas as enormes dificuldades que enfrentavam, a escassez de pessoal técnico qualificado, assim como a falta de visão e experiência de seus dirigentes.

Um passo importante foi a entrada de Cuba, por meio desta Direção, na Organização Internacional de Normalização (ISO), o que permitiu ao país receber informações muito importantes, além do intercâmbio de experiências com outros países.

Para o ano de 1963 deu-se prioridade ao desenvolvimento das normas técnicas e ao estabelecimento de um sistema de informações técnicas.

Para 1964, a prioridade foi, novamente, o estabelecimento de normas técnicas, além de normas de qualidade para os produtos de exportação.

Che determinou também que o plano piloto de metrologia, já iniciado, deveria buscar soluções para os problemas práticos que se apresentavam na adoção do Sistema Métrico Decimal (SMD). Em Cuba, devido à influência norte-americana em nossa economia se usava o sistema inglês de medidas. A adoção do SMD era de particular importância para, gradualmente, viabilizar o comércio e a transferência de tecnologia com os países socialistas, assim como com países europeus que já empregavam este sistema. Em 1964, foi criado o Laboratório Central de Metrologia para o estabelecimento gradual de padrões nacionais de diferentes tipos de medição. Deu-se ênfase especial à calibração das balanças, a maioria das quais estava em estado lamentável. Ao mesmo tempo, em conjunto com a Direção de Capacitação, criou-se a Escola de Metrologia. Foi enviado um grupos de técnicos à URSS e à República Democrática Alemã para se prepararem nesta disciplina.

Também foi inaugurado nesse ano o Laboratório Central de Controle de Qualidade e organizados cursos para preparar pessoal nas empresas.

Ainda que o desenvolvimento da qualidade não tenha aparecido explicitamente entre as tarefas priorizadas pelo Che para o organismo, ela foi, sem dúvida, um dos aspectos em que ele mais insistiu, enfatizando seu carácter social.

Em 1964, ao presidir a delegação cubana à Assembleia Geral da UNCTAD, em Genebra, Suíça, Che visitou uma fábrica de relógios, ficando muito impressionado com as 
normas e controles de qualidade ali utilizados. Em uma reunião do Conselho de Direção do Ministério, ele nos informou sobre a visita e, na discussão que seguiu, disse uma frase de grande conteúdo social e político: A qualidade é respeito ao povo.

Nesta expressão, o Che sintetizava seu critério de que a qualidade não é apenas um problema econômico, mas também um problema político, ideológico, social, ético e cultural, que não se pode nem se deve analisar separadamente.

O Che havia sido muito crítico sobre a falta de qualidade de muitos produtos causada, em parte, pelos problemas de obtenção das matérias-primas, mas, também pela falta de preocupação das empresas para fabricar algo melhor com os recursos disponíveis. Esses problemas decorriam da improvisação ao substituir materiais e matérias-primas submetidas ao bloqueio, assim como à indolência e falta de interesse de dirigentes e técnicos das empresas.

Em 1964, Che deu orientações concretas para que o Departamento de Controle de Qualidade fizesse inspeções frequentes nas fábricas e lojas comerciais para detectar problemas e que, em casos evidentemente graves, este departamento tivesse autoridade suficiente para interromper a produção. Assim o fizemos.

Pouco tempo depois, a equipe de Direção do Ministério de Comércio Interior realizou uma reunião com o Che e com a equipe do Ministério de Indústrias para mostrar a baixa qualidade de vários bens de consumo que distribuíam e que eram produzidos por nossas fábricas. Levaram amostras defeituosas de roupas, móveis e brinquedos, entre outras. Che pediu que deixassem todas essas amostras e convocou uma reunião de urgência com todas as empresas. Preparou-se uma exibição com todos esses produtos e com umas fotos tomadas pelo Departamento de Controle de Qualidade. A "descarga" foi grande, ele estava muito irritado.

Eu me senti mal, porque, mesmo não sendo essa "descarga" dirigida a minha área de trabalho, mas às empresas, senti que minha responsabilidade em atender ao controle da qualidade não tinha sido cumprida integralmente. Nossa atividade em relação à qualidade deveria enfatizar mais os aspectos educativos, além de promover um maior controle preventivo. Assim começamos a promover a criação de laboratórios de controle nas diferentes empresas.

Ainda que o Che tenha desatado uma árdua batalha para melhorar a qualidade dos produtos industriais, este é um problema ainda não solucionado satisfatoriamente, exceto nas indústrias farmacêutica - particularmente a biotecnológica -, mecânica, eletrônica e alguns 
produtos de exportação, com a introdução das normas ISO e das boas práticas de laboratório e de produção, entre outras medidas. A produção de bens para o consumo interno ainda está longe de ser satisfatória. Vários fatores negativos têm influenciado na solução da melhoria da qualidade:

- A insegurança e instabilidade do fornecimento de matérias-primas e materiais;

- A necessidade de produzir, de qualquer forma, para atender à população, com o consequente relaxamento progressivo da disciplina tecnológica;

- A vigência, durante muitos anos, de mecanismos e critérios de planificação, quando o cumprimento do plano de produção era o elemento principal de avaliação, sem considerar aspectos qualitativos;

- Um mercado de exportação para os países membros do CAME, geralmente pouco exigente quanto às especificações qualitativas;

- A ausência de controles internos e penalidades por descumprimento de normas de qualidade;

- A consequente formação de uma cultura produtiva, particularmente em alguns setores, em que as normas qualitativas tornaram-se de menor importância;

- A indolência de dirigentes e complacência - sempre colocando a culpa no bloqueio.

Alguns desses fatores derivam-se de dificuldades que persistem desde o início dos trabalhos de normalização na indústria; outros se originaram em práticas e procedimentos organizativos e administrativos que não consideram a qualidade como critério básico de produção. É fato que houve avanços, mas muito menos do que o necessário. Porém, é importante destacar que buscar um nível de qualidade adequado e que corresponda às necessidades econômicas, em um contexto cada vez mais exigente e competitivo, com uma perspectiva humana e social, como propugnava o Che, continua sendo uma tarefa prioritária.

O chefe da Direção de Normas, Metrologia e Controle da Qualidade era uma persona séria, organizada e trabalhadora. Em meados dos anos 70, a Direção se converteu no Comitê Estatal de Normalização, subordinado ao Conselho de Ministros. Mais tarde, tornou-se a Oficina Nacional de Normalização, vinculada à Junta Central de Panificação.

\section{A Direção do Plano para o Desenvolvimento Técnico}


A função principal desta Direção era colaborar, controlar, coordenar e avaliar o cumprimento do Plano para o Desenvolvimento Técnico de todo o Ministério. Para 1963, o Che orientou que se devia colaborar estreitamente com a Direção do Plano Perspectivo, de forma a ter uma visão geral das ações do Ministério, entre as quais estavam as ações de todo o Vice ministério, e traçar os esquemas de trabalho para atender às necessidades identificadas. Em 1964 deu-se início a um Plano Piloto de Desenvolvimento Técnico.

Che aspirava a que o Ministério em seu conjunto, em todas suas empresas e fábricas, alcançasse um adequado desenvolvimento científico e tecnológico. Isso tinha que resultar do trabalho dos institutos, do desenvolvimento das próprias empresas e de uma interação estreita entre esses atores. Assim, a ação do Vice ministério para o Desenvolvimento Técnico deveria ter um sentido mais global.

Devo confessar que, nos primeiros momentos de minha atuação como Vice-ministro desta área, eu não compreendi adequadamente essa visão integral. Concentrei-me, principalmente, em atender e impulsionar o surgimento dos diferentes institutos sob minha responsabilidade, o que já tomava praticamente todo meu tempo.

\section{Cultura Científica e Técnica: as publicações}

Além do que era realizado por meio das atividades diretamente relacionadas à produção, à pesquisa e ao desenvolvimento tecnológico, o Ministério tratava de criar e fortalecer uma cultura produtiva, científica, técnica, econômica e política em todos os níveis. Para isso, teve um papel importante a criação de três revistas:

- Nuestra Industria, dirigida a todos os trabalhadores do Ministério. Apresentava, de forma ampla e compreensível o trabalho do organismo e as dificuldades do momento. Era uma publicação ágil e amena, com uma impressão modesta, mas agradável. A coleção de Nuestra Indústria é um material de referência obrigatório para quem queira fazer uma história detalhada do Ministério de Indústrias.

- Nuestra Indústria Económica era uma revista de caráter mais acadêmico, utilizada para debater os problemas econômicos de maior importância de nosso desenvolvimento. Nela o Che publicou vários artigos sobre suas ideias e conceitos teóricos sobre o Sistema Orçamentário de Financiamento. Esses artigos deram oportunidades para a 
participação de outros dirigentes, como o então Ministro de Comércio Exterior e o Presidente do Banco Nacional de Cuba, os quais rebatiam os pontos de vista do Che, abrindo um debate teórico de alto nível e interesse.

Esses debates revelam um aspecto importante da personalidade do Che. Quando um participante que contestava algumas ideias do Che sobre a economia foi substituído no Ministério do Comércio Exterior, Che o convidou para como seu assessor no Ministério de Indústrias, com a função principal de continuar sendo seu oponente, seu "advogado do diabo", no tocante ao sistema de financiamento, enfim, um assessor para contradizer ao chefe!

- Nuestra Industria Tecnológica. Vale a pena reproduzir in extenso o editorial escrito pelo Che para o primeiro número desta revista. Nele se encontra um quadro sintético de seu pensamento quanto ao processo enfrentado pela Revolução Cubana e, em particular, do desenvolvimento industrial e do papel da ciência e da tecnologia em Cuba:

(A revista) está destinada fundamentalmente a nossos técnicos e a todos aqueles companheiros trabalhadores e estudantes que se preparam (...) a assumir cargos de responsabilidade nas indústrias em que trabalham e nas que vierem a ser criadas; é também a tentativa de estabelecer uma comunicação direta, por meio da tecnologia, com todos os países do mundo (...)

A tarefa da Revolução cubana tem sido grande no curto lapso de tempo entre o primeiro de janeiro de 1959 e este mês do ano 62 em que nasce a revista. Tivemos que destruir os restos do aparato estatal anterior, lutar contra o imperialismo, resgatar todas as empresas para o povo, destruir a superestrutura completa em que se baseava a dominação do regime anterior, lutar contra o bloqueio, aceitar o êxodo contínuo de nossos melhores técnicos, no sentido científico, e criar e desenvolver os existentes, baseando-nos no entusiasmo infatigável de uns quantos pioneiros que permitiram, em cada uma dos ramos industriais do país, cumprir com o povo neste momento difícil.

A técnica cubana está finalizando sua etapa mais dura (...) que foi a de tapar buracos, tratar de fazer com que o que existia e caminhava seguisse caminhando; buscar a forma de substituir um parafuso por um arame, um solvente por outro (...) enfim, fazer maravilhas para que, pelo método de aproximações sucessivas, nossas máquinas pudessem seguir caminhando. Mas, naturalmente que este é um sistema absurdo se se pretende seguir indefinidamente nele. Já nossos técnicos estão dedicados à segunda tarefa que é a importante e fundamental neste momento: criar tecnologias adequadas para processar as matérias-primas cubanas e as que nos vêm do estrangeiro (...) e, ao mesmo tempo, estabelecer uma tecnologia adequada para fazer boas peças de reposição (...) É uma tarefa mais previsora e de maior envergadura. Tomará um tempo desenvolve-la a fundo (...). Mas ainda assim, devemos já prepararmos para entrar na terceira que é a de desenvolver tecnologias que nasçam de nosso solo, de nossas matériasprimas, de nosso ambiente cultural e de nosso desenvolvimento atual, para poder dar ao mercado cubano e ao mercado mundial, os produtos de nosso solo elaborados até o máximo permitido pela técnica, de acordo com a criatividade e a ciência de nossos próprios tecnólogos. Aspiramos sinceramente, revolucionariamente, a que o trabalho de todos converta esta revista, no menor tempo possível, na expressão de um povo que caminha rapidamente pelas amplias vias da ciência moderna para um desenvolvimento industrial avançado. (Guevara 1966k, pp. 719-722). 
Esse editorial, escrito depois de três anos do triunfo da Revolução, constitui um documento programático de política industrial, científica e tecnológica. Não era pura retórica, e se converteu rapidamente em ações e medidas concretas.

\section{Uma Síntese da Atividade Científico-Técnica no Ministério de Indústrias}

Entre as múltiplas facetas da atividade do Che à frente do então Ministério de Indústrias, uma das menos conhecidas e divulgadas, foi relativa ao impulso sustentado ao desenvolvimento científico e tecnológico nacional. Foram criadas instituições que abarcavam de maneira integral distintas atividades dirigidas a articular a inovação tecnológica expressão ainda não utilizada naquela época - como parte da estratégia de desenvolvimento do organismo; fomentou-se o desenvolvimento tecnológico não apenas nessas instituições, mas também dentro das próprias empresas; dedicou-se parte importante dos escassos recursos especializados disponíveis naqueles momentos a promover a atividade de pesquisa e desenvolvimento tecnológico; estimulou-se de maneira efetiva a participação das massas trabalhadoras na solução dos problemas práticos e perspectivos de suas fábricas; iniciou-se um forte processo investidor para criar novas capacidades industriais, modernizar as existentes e, em alguns casos, concluir a construção e colocar em atividade algumas instalações, como a conhecida façanha da planta de níquel de Moa.

Além disso, se fortaleceram as ações para desenvolver o controle da qualidade e a normalização; criando-se, inclusive no Ministério, o primeiro centro informação científicotécnica em Cuba.

A capacitação em todos os níveis se converteu em tarefa altamente priorizada, com resultados muito positivos. Che promovia a colaboração e interação com as universidades e a Academia de Ciências de Cuba. Juntos, fomos à Universidade de Havana para discutir programas de colaboração; com a Academia, iniciamos um trabalho de colaboração no campo da Geologia. Todas estas atividades foram concebidas de maneira integral e sistêmica, desde os níveis superiores até a base.

Como se pode observar neste artigo, o pensamento do Che, se caracterizava por uma visão ideológica integral de grande alcance. Suas concepções políticas, económicas e sociais e as relacionadas com o desenvolvimento científico e tecnológico estão estreitamente vinculadas e se levaram à prática. Suas ações neste sentido se derivaram do critério de que a 
formação de um Homem Novo e o desenvolvimento da ciência e a tecnologia eram os dois pilares fundamentais na criação da nova sociedade socialista.

\section{Bibliografía}

GUEVARA, Ernesto. Discurso a los estudiantes de medicina y trabajadores de la salud. 19 de agosto de 1960. Che Guevara habla a la juventud. Pathfinder, NY., 2001, p.43.

GUEVARA, Ernesto. Resumen del discurso en el acto de graduación de los alumnos de la Escuela de Superación Obrera Lenin. Revolución, 15 de diciembre. La Habana, 1962.

GUEVARA, Ernesto. Intervención en el Seminario sobre Planificación, Argelia, 16 de julio de 1963. En El Che en la Revolución Cubana. t. 6. Ministerio de la Industria Azucarera, 1966a.

GUEVARA, Ernesto. Tareas Generales para 1963. En El Che en la Revolución Cubana. t. 6. Ministerio de la Industria Azucarera, 1966b.

GUEVARA, Ernesto. Orientaciones para 1964. En El Che en la Revolución Cubana. t. 6. Ministerio de la Industria Azucarera, 1966c.

GUEVARA, Ernesto. Tareas Fundamentales para 1965. En El Che en la Revolución Cubana. t. 6. La Habana: Ministerio de la Industria Azucarera, 1966d.

GUEVARA, Ernesto. Informe del Instituto Cubano de Recursos Minerales. En El Che en la Revolución Cubana. t. 6. La Habana: Ministerio de la Industria Azucarera, 1966e.

GUEVARA, Ernesto. Prólogo al libro "La Geología de Cuba". En El Che en la Revolución Cubana. t. 6. La Habana: Ministerio de la Industria Azucarera, 1966f, pp. 741-743.

GUEVARA, Ernesto. Tareas Fundaméntales para 1965. En El Che en la Revolución Cubana. t. 6. La Habana: Ministerio de la Industria Azucarera, 1966g.

GUEVARA, Ernesto. Informe del Instituto Cubano de Desarrollo de Maquinarias. En El Che en la Revolución Cubana. t. 6. La Habana: Ministerio de la Industria Azucarera,1966h.

GUEVARA, Ernesto. Informe del Instituto Cubano de Investigaciones de los Derivados de la Caña de Azúcar. En El Che en la Revolución Cubana. t. 6. La Habana: Ministerio de la Industria Azucarera, 1966 .

GUEVARA, Ernesto. Informe del Instituto Cubano de para el Desarrollo de la Industria Química. E El Che en la Revolución Cubana. t. 6. La Habana: Ministerio de la Industria Azucarera, 1966j.

GUEVARA, Ernesto. Editorial. Nuestra Industria Tecnológica. En El Che en la Revolución Cubana. t. 6. La Habana: Ministerio de la Industria Azucarera, 1966k. 
SÁENZ, Tirso W. \& E. GARCÍA CAPOTE. Ernesto Che GUEVARA y el progreso científico-técnico en Cuba. Conferencias y Estudios de Historia y Organización de la Ciencia, No. 17. Centro de Estudios de Historia y Organización de la Ciencia La Habana, febrero, 1980.

SÁENZ, Tirso W. \& E. GARCÍA CAPOTE (1989): Ciencia y tecnología en Cuba. Antecedentes y desarrollo. Editorial Ciencias Sociales. La Habana;

SAENZ, Tirso W. O Ministro Che Guevara. Testemunho de um colaborador. Rio de Janeiro: Edit. Garamond, 2004.

SÁENZ, Tirso W. Biotechnology for medical applications: The: Cuban experience.

Science, Technology and Society, New Delhi, India, v. 10:2, p. 225-248, 2005.

VICEMINISTERIO PARA EL DESARROLLO TÉCNICO. Informe al Consejo de Dirección. (mimeo). Ministerio de Industrias. La Habana, 1964.

\section{Che Guevara e sua Contribuição ao Desenvolvimento Científico e Tecnológico em Cuba}

\section{Resumo}

Este artigo é um testemunho do autor que, como Vice-ministro para o Desenvolvimento Técnico, pode acompanhar Ernesto Che Guevara em seus momentos como Ministro de Indústrias em Cuba, o que explica suas referências e apreciações pessoais. Pretende-se mostrar aqui as concepções e consequentes ações do Che na esfera científico-tecnológica no Ministério, bem como problemas reais encontrados e resultados obtidos.

Palavras chave: Desenvolvimento Tecnológico; Che Guevara; Revolução Cubana.

\section{Che Guevara y su Contribución al Desarrollo Científico y Tecnológico en Cuba}

\section{Resumen}

Este artículo es un testimonio del autor que, como Viceministro de Desarrollo Técnico, puede acompañar a Ernesto Che Guevara en sus momentos como Ministro de Industria en Cuba, lo que explica sus referencias y apreciaciones personales. Se pretende mostrar aquí las concepciones y las acciones consiguientes del Che en el ámbito científico-tecnológico en el Ministerio, así como los problemas reales encontrados y los resultados obtenidos.

Palabras-clave: Desarrollo Tecnológico; Che Guevara; Revolución Cubana.

\section{Che Guevara and his Contribution to Scientific and Technological Development in Cuba}

\section{Abstract}

This article is a testimony of the author who, as Deputy Minister for Technical Development, can accompany Ernesto Che Guevara in his moments as Minister of Industries in Cuba, which explains his references and personal appreciations. It is intended to show here the conceptions and consequent actions of Che in the scientific-technological sphere in the Ministry, as well as real problems found and results obtained.

Keywords: Technological Development; Che Guevara; Cuban Revolution. 